\title{
“¿Ésta es la paz de Santos?”: el partido Centro Democrático y su construcción de significados alrededor de las negociaciones de $\operatorname{paz}^{* *}$
}

"Is this the peace of Santos?": the Centro Democrático party and the construction of meanings around peace negotiations

\author{
"Esta é a paz de Santos?": o partido Centro Democrático \\ e sua construção de significados das negociações de paz
}

\footnotetext{
* Sociólogo de la Universidad del Valle (Cali, Colombia). Becario de excelencia de la Maestría de Ciencias Políticas de la FLACSO-Ecuador, convocatoria 2014-2016 (en curso). Correo electrónico: jumacaicedofl@flacso.edu.ec

${ }^{* *}$ Este artículo deriva de la investigación Campaña permanente entre el fuego cruzado: insurrección y aprobación presidencial en Colombia, iniciada en septiembre de 2015 como requisito para obtener el título de magíster en Ciencias Políticas en la Facultad Latinoamericana de Ciencias Sociales (FLACSO)-Sede Ecuador. Dicho proyecto se encuentra actualmente en etapa de revisión y corrección. Artículo de investigación recibido el 26/01/2016 y aceptado el o7/06/2016.
} 


\section{Cómo citar}

CAicedo AtehortúA, J. M. (2016). “EÉsta es la paz de Santos?”: el partido Centro Democrático y su construcción de significados alrededor de las negociaciones de paz. Revista CS, no. 19, pp. 15-37. Cali, Colombia: Facultad de Derecho y Ciencias Sociales, Universidad Icesi.

DOI: http://dx.doi.org/10.18046/recs.i19.2136 
Este trabajo parte de preguntarse cuáles han sido las estrategias discursivas adoptadas por el partido Centro Democrático de Colombia y sus simpatizantes con respecto a las negociaciones de paz entre el gobierno Santos y las FARC. Argumenta que estas estrategias se han basado en la descalificación del presidente Santos y su proyecto, partiendo de una re-significación de los conceptos de "paz" y “justicia”. Desde un marco analítico que recurre a Bourdieu y Van Dijk, observa el campo político como un campo de luchas por ideas y luchas entre poderes, donde los grupos hacen ingentes esfuerzos por darle resonancia social a sus discursos. Así, se lee al Centro Democrático como un conjunto de agentes que buscan capital político expresado en reconocimiento y poder dentro del Estado, a la vez que compite por unos objetos intelectuales, por la imposición de unos principios de visión y división alrededor de la paz y la justicia.

PALABRAS CLAVE:

Centro Democrático | Uribismo | proceso de paz | campo político | Colombia

This work studies the discursive strategies that have been adopted by the Centro Democrático party and its supporters regarding the peace negotiations between FARC and the Santos Government. I argue that these strategies have been based on the disqualification of President Santos and his project, starting with a re-signification of the concepts of "peace" and "justice". From an analytical framework that uses Bourdieu and Van Dijk, I see the political field as an arena of struggle for ideas and struggles between powers, where groups make great efforts to give social resonance to their speeches. Thus, I see the Centro Democrático as a group of agents seeking political capital expressed in recognition and power within the State, at the same time that it competes for intellectual objects by the imposition of some principles of vision and division around peace and justice.

\section{KEYWORDS:}

Centro Democrático | Uribismo | Peace process | Political field | Colombia 
Este trabalho parte de perguntar-se quais têm sido as estratégias discursivas que foram adotadas pelo partido Centro Democrático da Colômbia e seus simpatizantes com respeito às negociações de paz entre o governo Santos e as FARC. Argumenta que estas estratégias foram baseadas na desqualificação do presidente Santos e seu projeto, partindo de uma ressignificação dos conceitos de "paz" e "justiça". Desde um marco analítico que recorre a Bourdieu e Vam Dijk, observa o campo político como um campo de lutas por ideias e lutas entre poderes, onde os grupos fazem ingentes esforços por dar ressonância social aos seus discursos. Assim, se lê o Centro Democrático como um conjunto de agentes que buscam capital político expresso em reconhecimento e poder dentro do Estado, ao mesmo tempo em que compete por uns objetivos intelectuais, pela imposição de uns princípios de visão e divisão ao redor da paz e da justiça.

PALAVRAS CHAVES:

Centro Democrático | Uribismo | Processo de paz | Campo político | Colômbia 


\section{Introducción}

De acuerdo con autores como Van Dijk (2001: 72) y Bourdieu (2001a: 48), desde las palabras es posible construir realidad social, formando grupos y definiendo las pautas de interacción entre los mismos. En las luchas políticas están en juego objetos intelectuales, principios de visión y división del mundo expresados en el discurso global de los partidos y movimientos. Se trata, al mismo tiempo, de luchas entre ideas y entre poderes. A la luz de Bourdieu (2001a), cabría decir que los agentes políticos se disputan poder dentro del Estado a la vez que compiten por la imposición de unas referencias y unos significados en el campo político. Esto significa que la lucha política es en gran medida una lucha simbólica: una competencia por dar sentido al mundo a partir de la construcción y la imposición de unas formas simbólicas.

En este trabajo me pregunto "¿Cuáles han sido las estrategias discursivas que ha desplegado el partido Centro Democrático de Colombia con respecto a las negociaciones de paz entre el gobierno Santos y las FARC?". Tomo el concepto de "estrategias discursivas" como lo aplica el ecuatoriano Carlos De la Torre (1993), quien señala que cada discurso político está encaminado a la búsqueda del poder estatal y a la refutación y descalificación de un discurso opositor. Considero interesante este choque entre ideas y poderes porque brinda la oportunidad de observar la "magia social" de la que habla Bourdieu (2001a): el poder de actuar sobre el mundo a través de las palabras. Recolecto información de prensa y redes sociales y, a partir del análisis de la misma, planteo que desde el Centro Democrático se han redefinido conceptos y se han construido "mitos" y lemas encaminados a descalificar al gobierno Santos y su proceso negociador. A lo largo del documento, iré mostrando algunos de los contenidos en los que se evidencian estos ejercicios de poder simbólico.

\section{Contextualización}

El campo político colombiano quedó marcado desde 2002 por la irrupción de un agente que se lanzó a elecciones por fuera de los partidos tradicionales y que, en lugar de hablar de "paz", prefería hablar de "seguridad". El concepto de seguridad de Álvaro Uribe, como han señalado varios autores, es "tradicional" y "militar", es decir, se limita al uso de la fuerza para garantizar la existencia del Estado, de la sociedad y de los individuos. La prioridad es el ejercicio de una autoridad efectiva que disuada a los violentos. La exclusión, la discriminación y la desigualdad, por ejemplo, no son problemas urgentes en este trabajo de construir la seguridad (Atehortúa, 2007). 
Este concepto de seguridad fue el eje alrededor del cual se gestionó el problema de la insurrección en Colombia entre los años 2002 y 2010, durante el "gobierno redentor" de Álvaro Uribe, como lo define el exministro e ideólogo uribista Fernando Londoño (2015). Encuestadoras como Gallup (2014) llegaron a registrar el "mayor optimismo colectivo nacional" y los que son, hasta hoy, los niveles más altos de aprobación que haya obtenido un presidente en Colombia. El "poder militar percibido" de las FARC disminuyó considerablemente, es decir, el público evaluador consideraba imposible que esta guerrilla tomara el poder por la fuerza.

Para lograr la "conquista emocional" (Burbano de Lara, 2003:36) de la población colombiana, el discurso de la Seguridad Democrática apeló a sentimientos de seguridad, confianza y auto-estima. Estos sentimientos están basados en una relación personal de protección y dominación: el tutelaje y el amor del líder que llega con su "mano dura" y su "corazón grande". El Uribismo, ahora como Centro Democrático y como fuerza opositora al Gobierno, presenta con nostalgia esos sentimientos en sus videos de propaganda, como el que se cita a continuación. Quien habla representa a un tendero de unos 60 sesenta años:

Últimamente miro hacia atrás, como cuando uno extraña, caminábamos tranquilos, confiábamos en el otro, y sentía que no estaba solo, me hacen falta esos días, ipero tú... nunca te fuiste! Quiero de vuelta lo que me hiciste sentir, quiero volver a confiar, por eso, hoy voto por ti: Álvaro Uribe-e interviene la voz de Uribe:-“Vote por el Centro Democrático. Acompáñenos” (Centro Democrático - Comunidad Oficial. Cuenta oficial de Facebook. Publicado el: 16 de octubre de 2015).

Los sondeos de opinión han servido como herramienta para reforzar esta imagen, al reportar descensos en el "optimismo colectivo" e incrementos en el "poder militar percibido" de las guerrillas desde 2010, el año en el que Juan Manuel Santos asumió el poder (Gallup, 2014). Los actuales uribistas se han apropiado de estos resultados de los sondeos de opinión y percepción ciudadana y los han usado como instrumento político en pro de aspiraciones políticas y electorales. La sensación de inseguridad generalizada durante el gobierno Santos puede ser leída como un éxito del ejercicio de poder simbólico (Bourdieu, 2001b) por parte del Centro Democrático. El partido ha servido de aparato para imponer formas simbólicas y sembrar dudas y polémicas en el campo político: le ha dado forma e identidad a todo un colectivo que se rebela contra la manera como Juan Manuel Santos está gestionando temas como la insurrección y las relaciones internacionales. Como expongo a continuación, la "lucha por ideas" entre el gobierno Santos y el Centro Democrático gira alrededor de los conceptos de "paz" y "justicia”, los cuales son cuestionados y replanteados constantemente por esta fuerza opositora.

En su trabajo de producción discursiva, los uribistas adaptan sentidos a unas situaciones y las dotan de un significado, dentro de lo que podríamos llamar el discurso global 
del partido Centro Democrático (Van Dijk, 2001). Como los guiños en Geertz (2007), eventos/situaciones tales como un proceso de paz y una decisión jurídica pueden interpretarse de maneras muy distintas desde cada discurso global. Este discurso global, a su vez, está encaminado a una acción global de partido: hacer oposición a los acuerdos de paz de La Habana, una acción a la que los participantes pueden contribuir apoyando marchas y mítines, votando en elecciones y plebiscitos, uniéndose a la "resistencia civil", etc. Entre los participantes del discurso y la acción global del partido hay agentes profesionales del campo político, como los parlamentarios, que buscan la resonancia social a través de medios como la televisión y las redes sociales. Sin embargo, en la producción y difusión del discurso político no son menos importantes los militantes de base, quienes, una vez convencidos, permiten avanzar en la búsqueda de los "interesados" y los "indecisos" (Richard, 2011: 143-4). Por esta razón, en el análisis de la "lucha por ideas" alrededor de la paz y la justicia tengo en cuenta la voz oficial del Centro Democrático, así como declaraciones de sus seguidores y publicaciones en fanpages no oficiales de Facebook como "Viva Uribe” y "Álvaro Uribe - El Gran Colombiano".

\section{Paz: “¿Ésta es la paz de Santos?”}

La misma fundación del Centro Democrático en el año 2012 fue un acto de protesta contra el anuncio formal del gobierno Santos de que entablaría una mesa de negociaciones con las FARC. Al respecto, los uribistas sostienen que la paz no nace de la negociación, sino de la imposición de la autoridad estatal. Desde esta lógica, cuando el Estado abre procesos de diálogo, los terroristas lo toman como una muestra de blandura y debilidad y someten el proceso a la burla (Ramírez, 2011). Uribe ha definido el proceso actual como un "chiste", por el hecho que las guerrillas "siguen avanzando en el narcotráfico, en la extorsión, asesinando los soldados y los policías, y blanden como un trofeo la pierna de un soldado mutilado" (El Espectador, 2015).

En cualquier contexto de violencia armada, la palabra "paz" podría evocar ideales de optimismo y esperanza. La magia social ejercida desde las estrategias discursivas del Centro Democrático ha consistido en "revolucionar" esta palabra, darle la vuelta para que evoque sentimientos de escepticismo y desconfianza, para que recuerde constantemente el fracaso del gobierno de Pastrana (1998-2002) en un proceso similar. Con un ánimo de crítica, burla y descalificación, se refieren al actual proceso de negociación como la "paz de Santos". La fórmula mágica y política "paz de Santos" parodia la palabra "paz" y la resignifica como expresión de un gobierno débil, que fue incapaz de controlar el terrorismo. Mientras el gobierno Santos trata de dibujar un escenario de diálogo y reconciliación, con estrategias como el "desescalamiento verbal del conflicto" (BluRadio, 2015), el Centro Democrático contextualiza la "paz de Santos" en un escenario de desorden, inseguridad e incertidumbre. La "paz de Santos" es la 
contraparte de la Seguridad Democrática, como lo representa un "meme" extraído de la cuenta de Twitter del abogado uribista Jaime Restrepo, mejor conocido como "El Patriota" (ver Figura No. 1).

Figura 1 | La "paz de Santos" y la "guerra de Uribe"
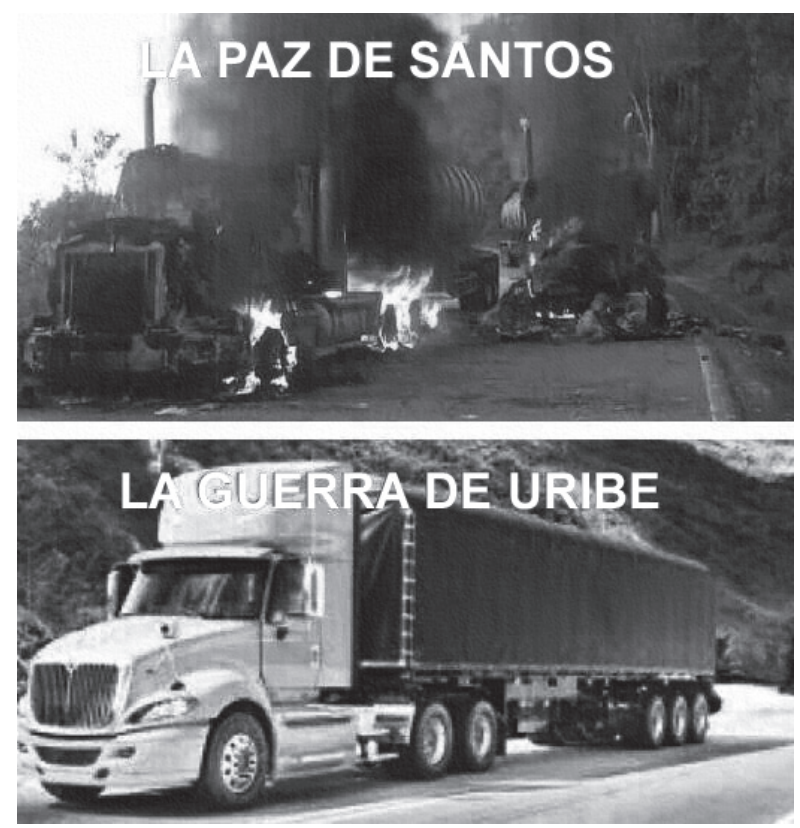

Fuente: @_El_Patriota, cuenta Twitter. Publicado el 2 de agosto de 2014.

Ponerle apellido a la paz y designarla como "paz de Santos" es presentarla como guerra. Un ejemplo de magia social similar al del totalitarismo orwelliano y su irónico lema: "la guerra es la paz" (Orwell, 2009). El Centro Democrático ha servido para que esta visión del mundo cobre resonancia en el campo político, tanto entre profesionales de la política como entre los que podríamos llamar "profanos" (Bourdieu, 2001a: 11, 20). Es un acto de magia, en el manejo del poder performativo de las palabras, lograr que un concepto signifique su antónimo, y darle a esta fórmula mágica y política una expresión visible (Bourdieu, 2001a: 43). Esta inversión de significados ha quedado sintetizada en la siguiente frase del exministro Fernando Londoño, de la que se ha hecho eco en redes sociales y en las columnas del periódico El Colombiano de Medellín: "La guerra de Uribe nos trajo la paz, la paz de Santos nos devolvió la guerra" (Londoño citado en De Toro, 2014). 
La pregunta “¿Ésta es la paz de Santos?” también se ha hecho tendencia en las redes sociales, apareciendo en los comentarios de todas las noticias que tienen que ver con las acciones subversivas (bajas de la Fuerza Pública, atentados terroristas, etc.). La difusión de un "hashtag" en internet, aunque parezca algo banal, no es un asunto de menor importancia. Esta frase es una unidad cultural: los que la replican comparten un significado concreto sobre la "paz de Santos", se ubican en una posición específica del espacio político (Martínez, 2014). Esta pregunta representa y explicita el reclamo de Uribe y sus seguidores con respecto a la actual negociación de paz. En esta pregunta, el discurso global del Centro Democrático expresa una inquietud y logra que todo un grupo de personas se aglomere alrededor de la misma. Cuando, sin necesidad de escuchar opiniones o directrices de los líderes del partido, sus militantes y seguidores operan bajo un mismo modelo de contexto (Van Dijk, 2001) y son capaces de interpretar eventos/ situaciones de forma parecida, se puede decir que se ha llegado a un conformismo lógico. Aquí, entonces, se observa el poder performativo del discurso en acción: en la formación de una comunidad de sentido, cuyos miembros son capaces de coordinar representaciones mentales y acciones sin necesidad de una comunicación permanente.

La fórmula "paz de Santos" ha tenido tal resonancia que desde el gobierno se han sentido en la obligación de reaccionar contra ella. En las cuentas oficiales de Juan Manuel Santos en Facebook y Twitter frecuentemente se hacen alusiones al respecto (ver Figuras 2 y 3). Quien escribe en estas cuentas seguramente no es el presidente Santos, sin embargo, es un community manager pagado por el gobierno que no puede decir cualquier cosa, sino que debe contextualizar los eventos/situaciones dentro del discurso global de dicho gobierno. La reacción discursiva del gobierno ha sido quitarle el apellido "de Santos" a la paz y presentarla como la paz "de todos los colombianos", como podemos ver en las Figuras 2 y 3.

La "lucha por ideas" que sostienen el gobierno Santos y el Centro Democrático alrededor de las negociaciones de La Habana trasciende la dimensión de las palabras y abarca también imágenes. La paloma blanca, ligada en el imaginario colectivo al concepto de paz, ha sido adoptada como emblema del gobierno y el presidente la lleva siempre como prendedor en su solapa, y ha regalado este mismo prendedor a personajes de fama mundial como el futbolista Radamel Falcao o el empresario Mark Zuckerberg (ver Figura 4). Sin embargo, cuando el director de la Policía, general Jorge Nieto, fue visto en entrevistas y actos públicos portando el prendedor, la senadora uribista María del Rosario Guerra recordó que este es un "logo de la campaña reeleccionista del santismo", el símbolo de una postura política, algo a lo que no se deberían vincular los miembros de la Fuerza Pública (Caracol Radio, 2016). Así como la "paz" es la "paz de Santos", para la legisladora uribista la imagen que la representa también está irremediablemente ligada a la persona del presidente y a su proceso negociador. 
La paz no es mi paz, no es la paz de Juan Manuel Santos, ni la paz de este gobierno. Es la paz de todos los colombianos.

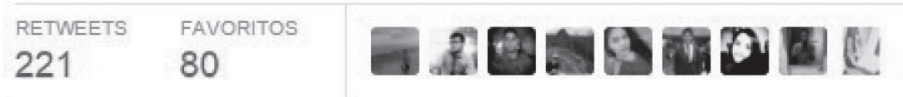

9:59 - 9 nov. 2013

Fuente: @JuanManSantos, cuenta oficial del presidente en Twitter. Publicado el 9 de noviembre de 2013.

FIGURA $3 \quad$ "Esta no es mi paz” II

Oskaresu "paz"es lo máximo...

Me gusta - Responder - 361 - 26 de septiembre a las $12: 58$

Juan Manuel Santos - Presidente $\odot$ Oskar, no es mi paz, es la paz de todos los colombianos. No puede ser mía porque yo necesito de la unidad del pais para alcanzarla, no puede ser mia porque si lo logramos será para que la disfrutemos todos. Lo invito a creer en una paz que es tan suya como mia. Feliz tarde.

Ya no me gusta - Responder - 389 - 26 de septiembre a las 13:10 - Editado

Fuente: "Juan Manuel Santos", cuenta oficial del presidente en Facebook. Publicado el 26 de septiembre de 2015. Los apellidos y la fotografía de este usuario de Facebook fueron ocultados por el autor de este artículo. 
FIGURA 4 $\mid$ Mark Zuckerberg recibiendo el prendedor de la paloma blanca

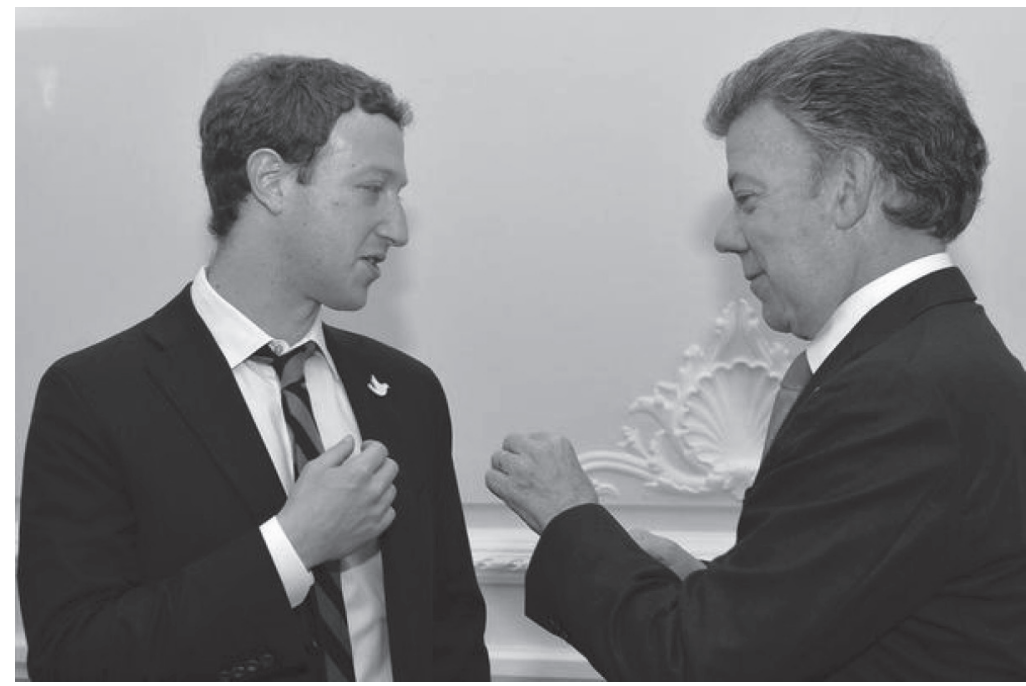

Fuente: Portafolio. Publicado el 14 de enero de 2015.

Operando bajo esta representación mental, en las páginas no oficiales de Facebook se comparten caricaturas de autores que no necesariamente son uribistas - y que de hecho critican y hacen burla de Uribe en otras ocasiones-, pero que comparten significados con esta comunidad de sentido. En una de estas caricaturas, obra de "Matador", la paloma blanca es representada no solo como un logo de Juan Manuel Santos, sino como una herramienta de distracción de la opinión pública, para que no resienta las alzas de impuestos (ver Figura 5). La caricatura, que puede encontrarse en el archivo virtual de El Tiempo, fue reproducida en enero de 2016 por la página "Álvaro Uribe - El Gran Colombiano", donde obtuvo 114 "me gusta” y la compartieron 128 usuarios, y la página "Viva Uribe", donde recibió 388 "me gusta" y fue compartida 331 veces. Este es un asunto de suma relevancia desde la teoría de la "memética", que observa los "memes" como unidades culturales que son replicadas dentro de internet porque los usuarios están de acuerdo con la información y el sentido que contienen (Martínez, 2014). En este caso, cientos de seguidores de Uribe consideran que el presidente Santos no solo se ha apropiado del concepto de "paz" y de la simbología que lo rodea, sino que recurre a estos elementos para ocultar problemas que tendrían los colombianos en otras áreas como la economía. A esta corriente de opinión se suman columnistas como Anastasia O'Grady, de The Wall Street Journal, quien acusa a Santos de estar buscando facultades para gobernar por decreto en nombre de la paz, y de haber planeado la dilatación de las negociaciones con las FARC con la intención de alargar su mandato (O'Grady, 2016). 
FIGURA 5 | "Empezó pesado el 2016", por "Matador"

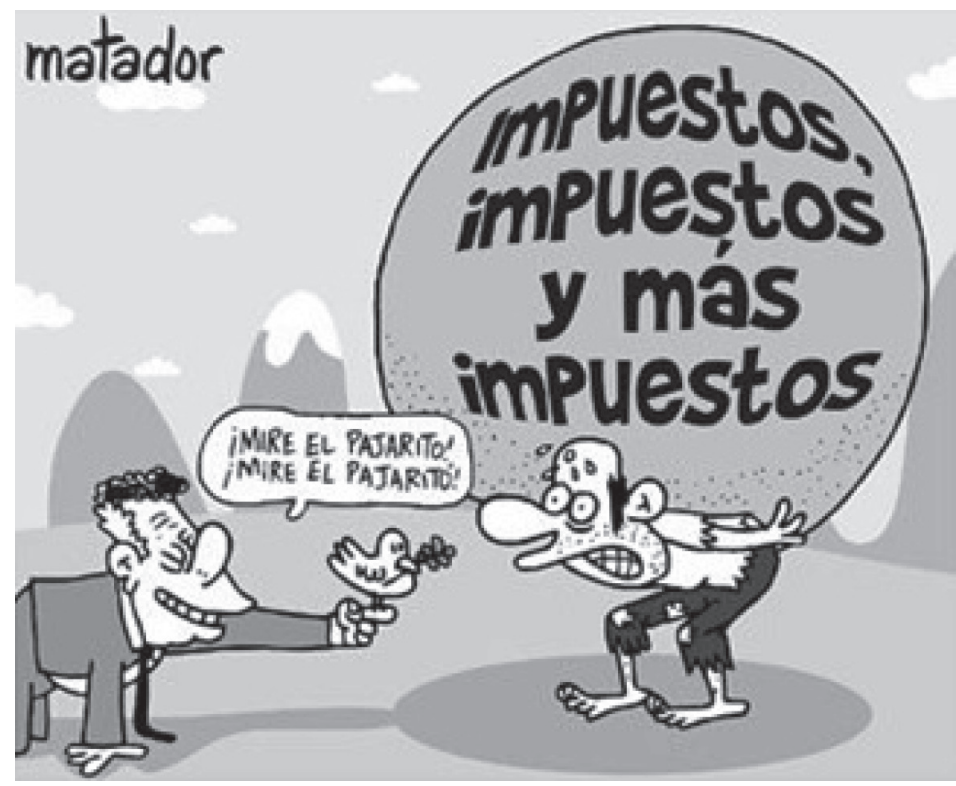

Fuente: El Tiempo Caricaturas. Sección "Matador”. Publicado el 7 de enero de 2016.

\section{Justicia: "impunidad" y"persecución política"}

En lo que se refiere a la justicia, el Centro Democrático ha adoptado una estrategia discursiva que podría ser definida como populista punitiva. El populismo punitivo utiliza el derecho penal como instrumento para generar sentimientos en la población a favor de aspiraciones políticas (Cotes y Fuentes, 2009). En la propuesta narrativa del Centro Democrático con respecto al fin del conflicto, que ocupa un lugar central en el discurso global del partido y en sus estrategias de campaña (Richard, 2015), el concepto de "paz" adquiere unos nuevos apellidos: "paz con castigo a los criminales" y "paz sin impunidad". Desde el partido de Uribe se insiste en que los jefes de las FARC deben pagar condena en cárceles y quedar inhabilitados para participar en política (El Tiempo, 2015).

La estrategia discursiva del Uribismo ha ido cediendo desde el rechazo total a las negociaciones de paz hacia la exigencia de unos requisitos para que las negociaciones se lleven a cabo. Las sanciones penales a los insurgentes han quedado en el centro de la agenda, en el eje de la propuesta narrativa sobre el fin del conflicto, y sobre esto se despliega la estrategia discursiva de tipo populista punitiva. En las vallas de campaña de Francisco Santos, candidato a la Alcaldía de Bogotá, se compara a Iván Márquez (ne- 
gociador de las FARC en La Habana) con otras figuras de la historia colombiana como el paramilitar Salvatore Mancuso y el narcotraficante Pablo Escobar, y se cuestiona que bajo el marco de la "paz de Santos" este personaje no recibiría el castigo que se merece o, en otras palabras, sus crímenes quedarían impunes (ver Figuras 6 y 7).

\begin{tabular}{|l|l|}
\hline FIGURA6 & Valla de campaña de Francisco Santos I \\
\hline
\end{tabular}

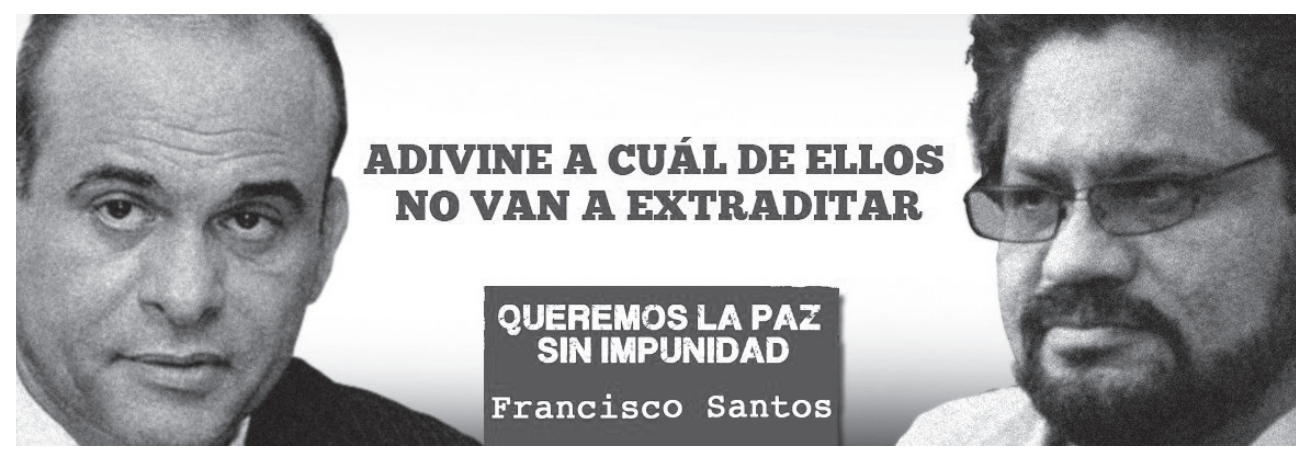

\begin{tabular}{|l|l|}
\hline FIGURA7 & Valla de campaña de Francisco Santos II \\
\hline
\end{tabular}

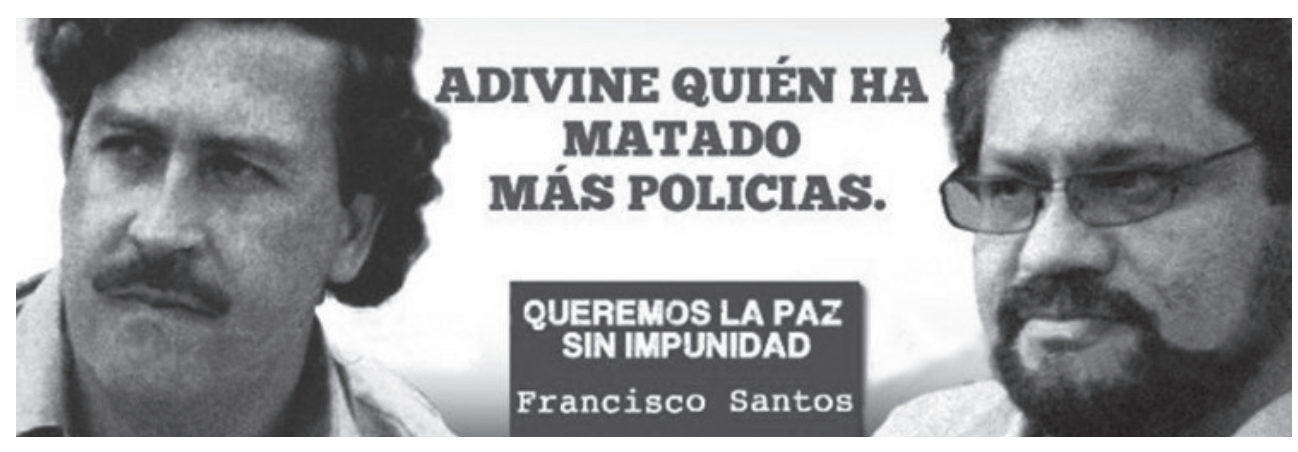

La FM. Publicado el 15 de abril de 2013.

Bajo esta fórmula mágica y política, el Centro Democrático convocó a la "Marcha por la Paz sin Impunidad", el 14 de diciembre de 2014. Aunque existen versiones y videos contradictorios sobre la asistencia a esta marcha (masiva o escasa), algunos medios afirmaron que esta movilización callejera convocó a miles de personas y que, solo en la Plaza de Bolívar de Bogotá, se llegaron a reunir unos seis mil manifestantes (Noticias Caracol, 2014). Como un marco interpretativo que diagnostica un problema, pronostica 
su solución y motiva a los actores a movilizarse (Benford y Snow, 200o), el Centro Democrático expone el proceso de paz de Santos como fuente de nuevos problemas más que como una solución, y convoca a sus seguidores a partir del principio movilizador de la sanción penal y carcelaria para los insurgentes/terroristas.

La estrategia populista punitiva y la propuesta narrativa que afirma que los miembros de las FARC no recibirán un castigo penal se ha visto reforzada por imágenes como las que muestran a los negociadores de esta guerrilla disfrutando de un viaje en yate, las cuales - sin que se sepa muy bien cómo se habrían filtrado - fueron publicadas justamente por la web Pensamiento Colombia, adscrita al discurso global del Centro Democrático (Caracol Radio, 2013). A esto se suman las declaraciones de "Timochenko", comandante de la organización guerrillera, quien dijo que solo accedieron a negociar porque Enrique Santos, hermano del presidente, les propuso pagar condena en Cuba con libertad de movimiento: "podemos ir a Varadero y volver a La Habana sin ningún problema" (Noticias RCN, 2015). La estrategia discursiva de este populismo punitivo ha sido tomar lo que el gobierno Santos ha presentado como mecanismos de justicia transicional y darle la vuelta para exponerlo como una paz con impunidad.

El discurso jurídico es la palabra creadora, el extremo hacia el que pretenden todos los enunciados performativos (Bourdieu, 2001a). Desde el campo político, el Centro Democrático ha querido construir discurso jurídico y ha luchado por el significado de lo que serán inocentes y culpables cuando se firme un acuerdo de paz. Para estos agentes políticos el problema no es solo que la justicia no actúa contra las FARC, sino que lo hace contra ellos en lo que definen como "persecución política". El partido no logra que su visión se transforme en discurso jurídico con poder de crear efectivamente lo que enuncia, sino que termina enfrentándose al proceso contrario: el discurso jurídico y el aparato de justicia del Estado colombiano son utilizados en su contra. Las investigaciones y condenas han ido ascendiendo hasta llegar a la cúpula uribista: exministros, el excandidato a la presidencia y hasta el mismo Uribe, quien está siendo investigado por una masacre ocurrida en 1997. La reacción del Uribismo ha sido adoptar un discurso "paranoide", caracterizado por la exageración y una cosmovisión apocalíptica y conspirativa (Gidron y Bonikowski, 2014).

Como otras formas de populismo, el Uribismo radicaliza el discurso maniqueo y adopta una visión de la política en términos de una relación amigo-enemigo (Gidron y Bonikowski, 2014: 8). En el comunicado oficial que anunció el lanzamiento de la campaña "Lo que es con Uribe, es conmigo", esta fuerza política unificó a sus enemigos dentro del eje "Santos, Maduro, Timochenko, Montealegre" (La FM, 2015). En esta fórmula, la palabra "Santos" representa al gobierno que le va a conceder a las FARC "un pacto de impunidad y elegibilidad". La palabra "Maduro" representa al enemigo externo, en el evento/situación de una crisis fronteriza en la que Uribe terminó cobrando protagonismo, visitando a los afectados y criticando desde todos los medios el manejo que 
le dio Santos a la situación. La palabra "Timochenko" alude al comandante en jefe de las FARC como principal representante del terrorismo. Y la palabra "Montealegre" se refiere a la Fiscalía, que ha emprendido la "persecución política" contra Uribe.

Resulta difícil imaginarse que las FARC son aliadas del presidente que ha ordenado bombardearlas, o que Nicolás Maduro es un amigo político de Juan Manuel Santos, con quien ha tenido fuertes enfrentamientos verbales. Así mismo, desde las normas establecidas se supone que la Fiscalía es una institución independiente que no actúa políticamente. La magia social del Uribismo en la identificación del enemigo radica en agrupar rivales que aparentan ser dispares o independientes unos de otros, y unificarlos en un enemigo singular. Este enemigo singular es un producto discursivo al servicio de una estrategia maniquea, de una propuesta narrativa conspirativa donde el enemigo puede estar en todas partes, incluso en instituciones que la Constitución y la teoría de la democracia presentan como autónomas con respecto al gobierno.

El discurso global del Centro Democrático parte de la premisa de que el poder judicial no está operando con independencia del ejecutivo y que la justicia está siendo utilizada como instrumento para atacar a Uribe y a su partido. El poder judicial, bajo esta lógica, ha sido cooptado por unos conspiradores que quieren cambiar los valores fundamentales de la nación (Gidron y Bonikowski, 2014). Los uribistas ven como héroes y víctimas de "persecución política" a militares ( $r$ ) como Luis Alfonso Plazas y Rito Alejo del Río, a los exministros Andrés Felipe Arias y Sabas Pretétl, a la ex directora del DAS María del Pilar Hurtado y, por supuesto, al mismo Álvaro Uribe y sus familiares. Cuando estos personajes son llamados a juicio y salen del país para no asumirlo, no se dice que han escapado de la justicia, sino que se han refugiado de una persecución política (ver figura 6).

En lo que tiene que ver con la justicia, el discurso del Centro Democrático establece un escenario caótico en el que el mundo está al revés: héroes militares y funcionarios públicos ejemplares son perseguidos, mientras los comandantes de las FARC toman el sol en La Habana. Por ello, no se puede confiar en el poder judicial colombiano y es la misma población la que tiene que salir en defensa de sus líderes. A esto apuntaba el lema adoptado por el partido en la campaña para las elecciones locales y regionales de 2015: "Lo que es con Uribe, es conmigo". La "persecución política" orquestada por el fiscal general Eduardo Montealegre debía ser contrarrestada votando por el Centro Democrático. Sin que quedara muy claro cuál sería la competencia de un alcalde o un gobernador en un proceso penal contra Uribe, se argumentó que la mejor manera de defenderlo era votando por sus candidatos.

Los lemas de los partidos políticos son un elemento fundamental. "Lo que es con Uribe, es conmigo" es otra fórmula mágica y política, que cumple con la función de simbolizar y sintetizar la cosmovisión del colectivo y de ahí pasar a su proceso de amplificación (Benford y Snow, 200o). Este lema recoge el carácter personalista del partido 
FIGURA 8 | "Persecución política”

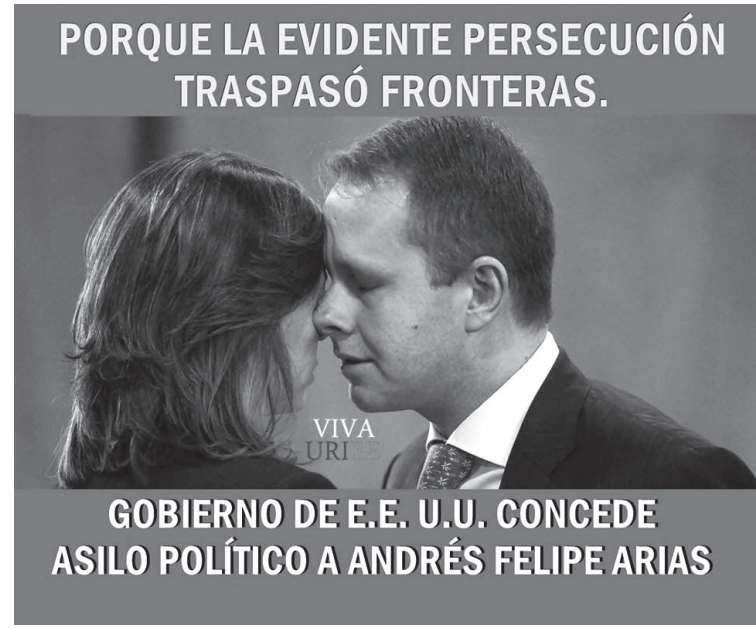

Fuente: "Viva Uribe", fanpage de Facebook. Publicado el 3 de mayo de 2015.

(Gunther y Diamond, 2003 y Panebianco, 1990), es decir, reafirma el carisma personal del líder como componente indispensable de la organización, al llamar a profesionales de la política y profanos a cerrar filas a su alrededor. Así mismo, reafirma la desconfianza en el poder judicial y la idea de la "persecución política". El lema, además, es en gran medida agresivo, hostil. Indica que todo lo que se diga o haga en contra del líder será tomado por el seguidor como una afrenta personal. Es un lema con un poder performativo: llama a la organización y la movilización de un grupo, en contra del propio Estado si es que llega a ser necesario. Durante la campaña de 2015, los miembros y simpatizantes del Centro Democrático usaron este lema en banderas, camisetas, vallas publicitarias y en las fotos de perfil de sus redes sociales (ver Figura 7).

Las decisiones jurídicas, como los guiños de los que habla Geertz (2007), son partículas de cultura que pueden ser significadas de múltiples maneras. Así, el Centro Democrático ha adoptado dos maneras de leer y contextualizar discursivamente dichas decisiones: "impunidad" cuando comprenden beneficios para las FARC en el marco de un proceso de justicia transicional, y "persecución política" cuando llaman a Uribe y a sus seguidores a responder por supuestos delitos que habrían cometido en el ejercicio de sus cargos públicos. Irónicamente, el grupo que recurre al populismo punitivo para incrementar su capital político, termina buscando en el capital político (reconocimiento y poder en el Estado) la fuerza necesaria para lidiar con la amenaza de la investigación y la sanción penal. En la propuesta narrativa del Centro Democrático, la justicia se 
FIGURA 9 | "Lo que es con Uribe, es conmigo"

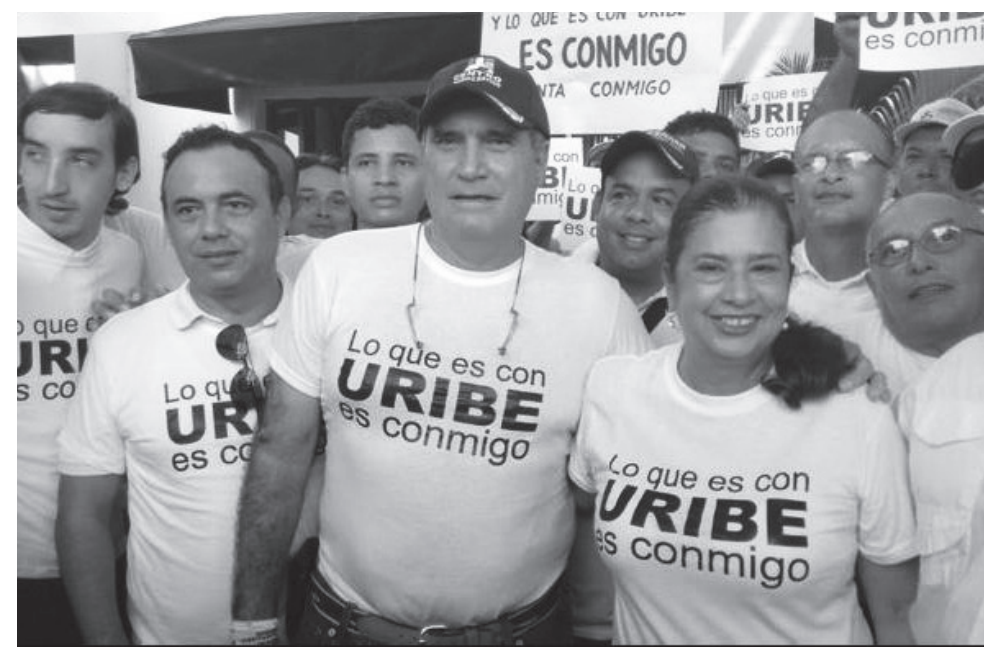

Fuente: Batista, Lía Miranda. El Universal. Publicado el 9 de octubre de 2015. La mujer en primer plano es Ginna Benedetti, candidata por el Centro Democrático a la Alcaldía de Cartagena.

transmuta en política: fiscales y jueces estarían operando basados en la relación amigo-enemigo, privilegiando a los miembros de las FARC y persiguiendo a los uribistas. A su vez, la política se transmuta en justicia: los candidatos del partido rodean a su líder ante el proceso penal que se inicia en su contra, y pretenden que lo defenderán mejor si ganan elecciones y llegan a ser alcaldes y gobernadores.

\section{Comentarios finales: conclusiones y nuevas preguntas}

El lenguaje y las formas simbólicas son fundamentales en la comprensión de la dinámica política. En el campo político se lucha por formas de ver y formas de creer. Como he tratado de mostrar, en el campo político colombiano hay una pugna entre dos formas diametralmente opuestas de ver la paz y la justicia: la del gobierno Santos y la del Centro Democrático. Aunque he enfocado este trabajo en analizar esta lucha por ideas en específico y las estrategias discursivas que el Centro Democrático ha empleado en la misma, no niego que en el campo político colombiano hay otras fuerzas con sus propias propuestas narrativas, que no necesariamente coinciden con las de Santos o Uribe, entre ellas las mismas FARC. Con respecto al Centro Democrático, considero que este partido ha actuado sobre el campo político a través de palabras re-significadas y fórmulas mágicas y políticas propias, aglomerando a una militancia que se cuenta en cientos de 
miles a pesar de tratarse de un partido joven (Cartagena, 2015), y contribuyendo a que el tema del fin del conflicto siga dominando la agenda de la opinión pública.

Los procesos de acumulación de capital político y simbólico son mutuamente dependientes. Para darle resonancia y visibilidad a sus significados, el Centro Democrático ha necesitado acumular fuerza política en la forma de reconocimiento y, más específicamente, en puestos dentro del Parlamento, reforzando el carácter de sus líderes como locutores autorizados para re-definir el mundo. A su vez, la difusión y la resonancia que logra la visión del mundo redundan en votos y reconocimiento, que contribuyen a fortalecer y reproducir el mismo aparato partidario. Capital simbólico y capital político no son fáciles de separar analíticamente, pues operan como dos engranes de la misma máquina: el aparato partidario. Desde la lógica de Bourdieu (2001a), podría afirmar que las luchas más relevantes se dan en el terreno de lo simbólico: es ahí donde se "manipulan" las mentes, se las llena de representaciones y se modifica la realidad.

Para Van Dijk (2001), los contextos y los discursos se influencian mutuamente. Los productores de discurso se ajustan a las variaciones del contexto y, a su vez, el contexto experimenta el impacto de los discursos que tienen mayor resonancia social. Las estrategias discursivas que el Centro Democrático ha venido desplegando desde su fundación, orientadas a la descalificación del gobierno Santos, tal vez no tuvieron suficiente poder de convocatoria como para ganar las elecciones presidenciales de 2014, o para obtener triunfos significativos en las regionales y locales de 2015. Sin embargo, los espacios que el partido ha ganado en el Parlamento y en la movilización callejera han llevado a que se lo vea como una de las mayores fuerzas políticas del país. En la revista Semana (2014) se describió al Centro Democrático como el "principal bloque opositor al gobierno" en el Congreso, algo que incluso soslaya el papel del Polo Democrático Alternativo, que hace oposición desde la izquierda y que lleva años proponiendo agendas de discusión que trascienden los temas de defensa y seguridad. La consolidación de la imagen del Centro Democrático como fuerza opositora a los acuerdos de La Habana no es un asunto de menor importancia: ante el evento/situación de que las negociaciones retrocedan, se rompan o no den los resultados esperados, el escenario podría reorientarse y ponerse a favor de los que siempre mantuvieron un discurso crítico y opositor con respecto a la "paz de Santos".

Como dato que atraviesa toda la reflexión, no se puede omitir que el Centro Democrático tiene los rasgos de un partido personalista y carismático: buena parte de su atractivo electoral se basa en el carisma personal del líder, concebido como indispensable para resolver los problemas del país (Gunther y Diamond, 2003 y Panebianco, 1990). El carisma de Uribe emergió en una situación de crisis en la economía y el orden público y durante sus años de gobierno este agente acumuló un capital político de tipo heroico o personal profético (Meichsner, 2007). Como es característico en un fenómeno carismático, la comunidad política uribista se unifica alrededor de su fe en 
el héroe extraordinario (Weber, 2002). El primer nombre que tuvo el partido (Uribe Centro Democrático), su logo (con la silueta del expresidente), la campaña "Lo que es con Uribe, es conmigo", todo esto son evidencias observables de una experiencia de liderazgo carismático. Este ingrediente personalista no sólo ha marcado al Centro Democrático sino a todo el espectro de la política colombiana, donde estar en contra o a favor de Uribe sigue siendo un aspecto crucial y definitorio para los políticos, aun cuando han pasado varios años desde que el expresidente dejó el poder.

Los políticos profesionales tienen un lenguaje clasificatorio. Cada discurso hace su propia construcción de la realidad social: toma elementos contextuales que le anteceden y a partir de los mismos representa escenarios, expone problemas, propone soluciones y convoca a unos participantes que tendrán roles de receptores, productores y reproductores del discurso. La realidad social y política construida desde el discurso consolida la militancia alrededor suyo, se ejerce el poder simbólico al configurar una fuerza a movilizar. Las estrategias discursivas apuntan a la consolidación de esta comunidad de sentido y a la vez emergen de la misma, y entre sus miembros se construye un conformismo lógico y moral a partir de unos principios comunes. En el caso de los uribistas, se podría decir que su comunidad de sentidos y significados se basa en los siguientes principios de visión del mundo: la lealtad a Uribe como héroe extraordinario, la sensación de que la seguridad ha empeorado desde que Santos asumió el poder, la desconfianza en el poder judicial colombiano y el escepticismo con respecto a la "paz de Santos".

He sostenido que las ideas sobre lo que deben ser la paz y la justicia han definido el debate alrededor de las actuales negociaciones entre el gobierno Santos y las FARC. Sin embargo, este artículo deja abiertas nuevas preguntas. En el campo político colombiano existen otras palabras mágicas de considerable poder performativo como "terrorista". Cuando fue presidente, Uribe llamó "terroristas de civil" a sus opositores de izquierda en un intento por descalificarlos como críticos (El Tiempo, 2007). El gobierno Santos ha promovido un "desescalamiento verbal del conflicto" que comprende, entre otras cosas, dejar de llamar "terroristas" a los miembros de las FARC (BluRadio, 2015). Y en el marco de un enfrentamiento verbal en el Congreso, el senador Roy Barreras, cercano al gobierno Santos, definió a los miembros del Centro Democrático como los "nuevos terroristas" de Colombia. Al día siguiente, Barreras pidió disculpas y matizó sus declaraciones (El País, 2015).

En el campo político colombiano, marcado por la violencia armada, la palabra "terrorista" define al enemigo, la amenaza y el problema a solucionar. Los uribistas mantienen esta fórmula en el núcleo de su estrategia discursiva: las FARC son terroristas y los defensores del actual proceso son tildados abiertamente de "aliados", "testaferros" o "cómplices" del terrorismo (Prensa Centro Democrático, 2016). Santos, por su parte, propuso erradicar esta palabra pero no logró impedir que uno de sus más insignes 
parlamentarios la utilizara a la ligera contra la oposición parlamentaria. "Terrorista" es la palabra mágica que designa al "otro", contra el que se lucha; es una palabra con poder performativo porque configura grupos y construye sentidos (Bourdieu, 2001b). De cara a futuras investigaciones, sería interesante indagar sobre los usos políticos que se le han dado en Colombia a este término.

\section{Referencias}

ATEHORTÚA, A. (2007). Las Banderas del Presidente Uribe. Bogotá, Colombia: La Carreta.

BENFORD, R. y SNOW, D. (200o). Framing Processes and Social Movements: An Overview and Assessment. Annual Review of Sociology, 26, 611-639.

BOURDIEU, P. (1985). ¿Qué significa hablar? Madrid, España: Akal Universitaria.

BOURDIEU, P. (2001a). El Campo Político. La Paz, Bolivia: Plural.

BOURDIEU, P. (2001b). ¿Cómo se hace una clase social? Sobre la existencia teórica y práctica de los grupos. En Bourdieu, Poder, derecho y clase social (pp. 101-131) Madrid, España: Palimpsesto.

BURBANO DE LARA, F. (2003). Democracia, cultura política y gobernabilidad. En F. Burbano de Lara (Comp.), Antología. Democracia, Gobernabilidady Cultura Política (pp.13-63) Quito, Ecuador: Flacso Ecuador.

COTES, C. y FUENTES, A. (2009). Populismo punitivo: incidencia actual en el contexto legislativo colombiano. Actualidad Jurídica, 4, 64-70.

DE LA TORRE, C. (1993). “La oración de José María Velasco Ibarra” en La Seducción Velasquista (pp. 183-205). Quito: Librimundo/Flacso-Ecuador.

GEERTZ, C. (2007). Descripción densa: hacia una teoría interpretativa de la cultura. En P. Bohannan y M. Glazer (Eds.), Antropología. Lecturas (pp. 547-568) Madrid, España: McGraw-Hill/Interamericana de España.

GIDRON, N. y BONIKOWSKI, B. (2014). Varities of Populism: Literature Review and Research Agenda. Working Paper Series of Weatherhead Center for International Affairs, Harvard University, 14, 1-38.

GUNTHER, R. y DIAMOND, L. (2003). Species of Political Parties. A New Tipology”. Party Politics, 9(9), 167-199.

MEICHSNER, S. (2007). El campo político en la perspectiva teórica de Bourdieu. Voces y Contextos, $3(2), 1-22$.

ORWELL, G. (2009). 1984. Barcelona, España: Destino. 
PANEBIANCO, A. (1990). Modelos de partido. Organización y poder en los partidos políticos. Madrid, España: Alianza.

RAMÍREZ, M. (2011). “Álvaro Uribe Vélez y el liderazgo racional carismático", Tesis de la Maestría en Sociología de la Facultad de Ciencias Humanas, Universidad Nacional de Colombia.

RICHARD, E. (2011). Storytelling, narrativas de campaña. Campañas electorales para la presidencia en Colombia, 2010. Opera, 11, 129-145.

RICHARD, E. (2015). Elecciones presidenciales en Colombia 2014: construcción de relatos de paz. Zero, 33 .

VAN DIJK, T. (2001). Algunos principios de una teoría del contexto. Revista latinoamericana de estudios del discurso, 1(1), 69-81.

WEBER, M. (2002). Economía y Sociedad. México D.F., México: Fondo de Cultura Económica.

\section{Webgrafía}

@_EL_PATRIOTA. Cuenta Twitter del abogado Jaime Restrepo, mejor conocido como "El Patriota". Ver_https://twitter.com/_el_patriota?lang=es

@JUANMANSANTOS. Cuenta oficial de Juan Manuel Santos en Twitter. Ver_ https://twitter.com/ juanmansantos?lang=es

ÁLVARO URIBE - EL GRAN COLOMBIANO. Página de Facebook. Ver: https://www.facebook. com/\%C3\%81lvaro-Uribe-El-Gran-Colombiano-619608014816536/?fref=ts

BATISTA, L. M. "Centro Democrático en Bolívar se une a campaña Lo que es con Uribe es conmigo", El Universal, Cartagena, 9 de octubre de 2015. Recuperado de: http://www.eluniversal.com.co/politica/centro-democratico-en-bolivar-se-une-campana-lo-que-es-con-uribe-es-conmigo-208140 (consultado el 24 de mayo de 2016).

BLURADIO (REDACCIÓN BLURADIO). "Santos propone desescalamiento verbal y no llamar a Farc bandidos o terroristas", BluRadio, 16 de julio de 2015. Recuperado de: http://www.bluradio. com/105257/santos-propone-desescalamiento-verbal-y-no-llamar-farc-bandidos-o-terroristas (consultado el 24 de mayo de 2016).

CARACOL RADIO. "Polémica por fotos de negociadores de Farc en un yate en Cuba", Caracol Radio, 3 de noviembre de 2013. Recuperado de: http://caracol.com.co/radio/2013/11/o3/nacional/138348066o_oo7183.html (consultado el 24 de mayo de 2016).

CARACOL RADIO. "Polémica por la paloma de la paz que lleva el director de la Policía en su uniforme", Caracol Radio, 17 de marzo de 2016. Recuperado de: http://caracol.com.co/radio/2016/o3/17/ politica/1458171077_936886.html (consultado el 24 de mayo de 2016). 
CARTAGENA, C. “725.925 militantes tiene el Centro Democrático", Minuto 30, 2 de marzo de 2015. Recuperado de: http://www.minuto3o.com/725-925-militantes-tiene-el-centro-democratico/314550/ (consultado el 24 de mayo de 2016).

CENTRO DEMOCRÁTICO-COMUNIDAD OFICIAL. Página oficial del partido Centro Democrático en la red social Facebook. Ver_https://www.facebook.com/CeDemocratico/?fref=ts

DE TORO, C. "La paz que nos devolvió la guerra”, El Colombiano, Medellín, 2 de octubre de 2014. Recuperado de:http://www.elcolombiano.com/la_paz_que_nos_devolvio_la_guerra-MFEC_313780 (consultado el 20 de enero de 2016).

EL ESPECTADOR (REDACCIÓN POLÍTICA). “Grave no es que se reúnan 'Timochenko’ y ‘Gavino' en Cuba, grave es lo que hacen en Colombia: Uribe”, El Espectador, Bogotá D.C., 12 de mayo de 2015. Recuperado de: http://www.elespectador.com/noticias/politica/grave-no-se-reunan-timochenko-y-gabino-cuba-grave-hacen-articulo-560077 (consultado el 18 de octubre de 2015).

EL PAÍS (COL.). “¿Se excusó Roy Barreras por tildar de terroristas a congresistas del Centro Democrático?”, El País, 7 de octubre de 2015. Recuperado de: http://www.elpais.com.co/elpais/colombia/ noticias/excuso-barreras-por-tildar-terroristas-centro-democratico (consultado el 24 de mayo de 2016).

EL TIEMPO. “De 'terroristas de civil' calificó el presidente Álvaro Uribe a políticos del desmovilizado M-19”, El Tiempo, Bogotá D.C., 4 de febrero de 2007. Recuperado de: http://www.eltiempo.com/ archivo/documento/CMS-3425653 (consultado el 24 de mayo de 2016).

EL TIEMPO. “Centro Democrático critica que jefes de Farc no tengan cárcel”, El Tiempo, Bogotá D.C., 23 de septiembre de 2015. Recuperado de: http://www.eltiempo.com/politica/partidos-politicos/ santos-y-farc-anuncian-acuerdo-de-justicia-en-proceso-de-paz-criticas-de-uribe/16385269 (el 24 de mayo de 2016).

EL TIEMPO CARICATURAS. Sección “Matador”. “Empezó pesado el 2016”, El Tiempo, Bogotá D.C., enero de 2016. Recuperado de: http://www.eltiempo.com/opinion/caricaturas/matador/16476386 (consultado el 24 de mayo de 2016).

GALLUP POLL COLOMBIA. (2014). Informe No.102. Descargable en: http://lasillavacia.com/archivos/historias/encuestas/gallup.pdf

JUAN MANUEL SANTOS. Cuenta oficial de Juan Manuel Santos en Facebook. Ver_https://twitter. com/juanmansantos?lang=es

LA FM. "Francisco Santos tendrá que retirar las vallas que ha puesto en el país”, La FM, 15 de abril de 2013. Recuperado de: http://www.lafm.com.co/noticias/francisco-santos-tendra-que-135533 (consultado el 24 de mayo de 2016).

LA FM. "Centro Democrático: lo que es con Uribe es conmigo", La FM, 9 de octubre de 2015. Recuperado de: http://www.lafm.com.co/pol\% $\mathrm{C}_{3} \% \mathrm{ADtica} /$ noticias/centro-democr\% $\mathrm{C}_{3} \% \mathrm{~A} 1 \mathrm{ti}$ co-que-es-urib-192309 
LA W. "Francisco Santos lanza nueva valla cuestionando extradición de Iván Márquez", La W, 12 de julio de 2013. Recuperado de: http://www.wradio.com.co/noticias/actualidad/francisco-santos-lanza-nueva-valla-cuestionando-extradicion-de-ivan-marquez/20130712/nota/1931961.aspx (consultado el 24 de mayo de 2016).

LONDOÑO, F. "Sin darnos cuenta, nos arruinó Juampa", Las 2 Orillas, 28 de diciembre de 2015. Recuperado de: http://www.las2orillas.co/sin-darnos-cuenta-nos-arruino-juanpa/ (consultado el 18 de octubre de 2015).

MARTÍNEZ, R. "El significado cultural del meme se propaga con el relajo cibernético", La Jornada, México D.F., 8 de julio de 2014. Recuperado de: http://www.jornada.unam.mx/2014/o7/o8/cultura/ ao7n1cul (consultado el 24 de mayo de 2016).

NOTICIAS CARACOL. "Paz sin impunidad pidieron miles de personas en marcha nacional”, Noticias Caracol, 14 de diciembre de 2014. Recuperado de: http://www.noticiascaracol.com/colombia/ paz-sin-impunidad-pidieron-miles-de-personas-en-marcha-nacional (consultado el 24 de mayo de 2016).

NOTICIAS RCN. "Timochenko: hermano de Santos nos dijo que podíamos cuadrar para no ir tras las rejas", Noticias RCN, 9 de octubre de 2015. Recuperado de: http://www.noticiasrcn.com/nacional-dialogos-paz/timochenko-hermano-santos-nos-dijo-podiamos-cuadrar-no-ir-tras-las-rejas

O'GRADY, A. “Opinión: La toma de poder de Santos en nombre de la paz”, The Wall Street Journal, 22 de mayo de 2016. Recuperado de: http://lat.wsj.com/articles/SB127398138613833139094045820 82980995234966 (consultado el 24 de mayo de 2016).

PORTAFOLIO (EMPRESAS). "Frases de Zuckerberg en su charla con el presidente Santos", Portafolio, 14 de enero de 2015. Recuperado de: http://www.portafolio.co/negocios/empresas/frases-zuckerberg-charla-presidente-santos-25774 (consultado el 20 de mayo de 2016).

PRENSA CENTRO DEMOCRÁTICO. “Gobierno le entrega la Constitución a Farc y se vuelve cómplice del grupo terrorista para hacer un Golpe de Estado a la democracia: Uribe”. Centro Democrático (página web oficial), Bogotá D.C., 13 de mayo de 2016. Recuperado de: http://www.centrodemocratico.com/?q=articulo/gobierno-le-entrega-la-constitucion-farc-y-se-vuelve-complice-del-grupo-terrorista-para (consultado el 24 de mayo de 2016).

SEMANA. "El Centro Democrático, la nueva oposición", Semana, 6 de diciembre de 2014. Recuperado de: http://www.semana.com/nacion/articulo/bancada-del-partido-centro-democratico-la-nueva-oposicion/411403-3 (consultado el 24 de mayo de 2016).

VIVA URIBE. Perfil de Facebook. Recuperado de: https://www.facebook.com/VivaUribePerfilOriginal?fref=ts (consultado el 22 de mayo de 2016). 